\title{
The skin function: a factor of anti-metabolic syndrome
}

\author{
Shi-Sheng Zhou ${ }^{1 *}$, Da Li ${ }^{2}$, Yi-Ming Zhou ${ }^{3}$ and Ji-Min Cao ${ }^{4}$
}

\begin{abstract}
The body's total antioxidant capacity represents a sum of the antioxidant capacity of various tissues/organs. A decrease in the body's antioxidant capacity may induce oxidative stress and subsequent metabolic syndrome, a clustering of risk factors for type 2 diabetes and cardiovascular disease. The skin, the largest organ of the body, is one of the major components of the body's total antioxidant defense system, primarily through its xenobiotic/drug biotransformation system, reactive oxygen species-scavenging system, and sweat glands- and sebaceous glands-mediated excretion system. Notably, unlike other contributors, the skin contribution is variable, depending on lifestyles and ambient temperature or seasonal variations. Emerging evidence suggests that decreased skin's antioxidant and excretory functions (e.g., due to sedentary lifestyles and low ambient temperature) may increase the risk for metabolic syndrome. This review focuses on the relationship between the variability of skin-mediated detoxification and elimination of exogenous and endogenous toxic substances and the development of metabolic syndrome. The potential role of sebum secretion in lipid and cholesterol homeostasis and its impact on metabolic syndrome, and the association between skin disorders (acanthosis nigricans, acne, and burn) and metabolic syndrome are also discussed.
\end{abstract}

Keywords: The skin, Antioxidant defense, Xenobiotic, Lipid homeostasis, Sedentary lifestyle, Metabolic syndrome, Acanthosis nigricans, Acne

\section{Introduction}

The metabolic syndrome (MetS), which is characterized by obesity, insulin resistance, dyslipidemia, and hypertension, is thought to be a driver of the modern-day epidemics of type 2 diabetes and cardiovascular disease [1,2]. Over the past few decades, there has been an alarming increase in the prevalence of MetS. Approximately one third of the adult population in developed countries can be categorized as having MetS by different definitions [3]. Most evidently, the rise of the epidemic of obesity, a major component of MetS, seemed to begin almost concurrently in most highincome countries in the 1970s and 1980s, which is thought to result from changing global food system and increasingly sedentary lifestyles, especially the former [4]. However, the exact cause remains under investigation.

Oxidative stress, which is thought to play a central pathogenic role in the pathogenesis of MetS, is a condition

\footnotetext{
* Correspondence: zhouss@ymail.com

${ }^{1}$ Department of Physiology, Medical College, Dalian University, Dalian, 116622, China

Full list of author information is available at the end of the article
}

of oxidant/antioxidant imbalance in which the net amount of reactive oxygen species (ROS) exceeds the antioxidant capacity of the body [1,5]. Excessive ROS can react with cellular macromolecules and cause lipid peroxidation, protein oxidation, and oxidative DNA damage [1]. One of the major sources of ROS is xenobiotics which are exogenous chemicals, including drugs, environmental pollutants, cosmetics, and even components of the diet [6-8]. Notably, over the past few decades, excessive xenobiotic exposure has occurred in the general population, for example due to food additives and synthetic-nutrient supplements [9]. In this case, there is the possibility that xenobiotics might be involved in increased prevalence of MetS and related diseases [2].

The skin, which is the body's largest organ, plays a role in the metabolism and elimination of xenobiotics, endogenous bioactive substances, lipids, and cholesterol [10-15]. This review focuses on the relationship between the variability of skin-mediated detoxification and elimination of exogenous and endogenous toxic substances and the development of MetS. The potential role of

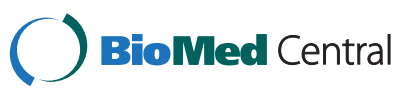


sebum secretion in lipid and cholesterol homeostasis and its impact on MetS, and the association between skin disorders (acanthosis nigricans, acne, and burn) and MetS are also discussed.

\section{Xenobiotics, oxidative stress and metabolic syndrome}

Xenobiotics, which are encountered by humans on a daily basis, undergo metabolism and detoxification to produce numerous metabolites, some of which have the potential to cause toxic effects [8]. Xenobiotics are degraded or biotransformed by two enzyme systems called phase I and II, and eliminated from the body through urine and sweat and other excretory pathways. The following evidence suggests a possible involvement of xenobiotics in the pathogenesis and prevalence of MetS.

1) Xenobiotic metabolism in the body generates ROS and high exposure to xenobiotics can lead to oxidative stress $[6,7,16]$.

2) The degradation of many xenobiotics involves methylation, a methyl-consuming reaction [2]. Therefore, high xenobiotic exposure may disturb the methylation of endogenous substrates due to competition for labile methyl groups. For example, excess nicotinamide (a form of niacin) can inhibit methylation-mediated degradation/inactivation of catecholamines, resulting in an increase in the levels of circulating norepinephrine [17], a phenomenon commonly seen in MetS [18], which provides the first evidence that methyl-consuming xenobiotics may contribute to increased circulating norepinephrine. In animal studies, arsenic, a common environmental methylconsuming toxin that increases the risk of MetS [19], is found to cause global DNA hypomethylation [20,21].

3) There has been increasing evidence that numerous xenobiotics, such as heavy metals $[7,19]$, organic pollutants [22-24], and long-term medications (e.g., atypical antipsychotic [25], anti-bipolar disorder [26], and anti-cancer medications [27]), may play a causal role in MetS.

4) Lipid metabolism also increases the demand for methyl groups (due to the synthesis of phosphatidylcholine from phosphatidylethanolamine) and methyl deficiency causes hepatic steatosis and subsequent plasma dyslipidemia [28]. Thus, high fat intake may have synergy with xenobiotics in the development of MetS.

5) Strictly speaking, synthetic vitamins also belong to the xenobiotic group, because excessive amounts of vitamins, such as niacin (nicotinamide and nicotinic acid) [29], vitamin D [30], vitamin E, and vitamin $K$
[31], are degraded by xenobiotic/drug-metabolizing enzymes. Our ecological evidence has suggested a strong positive lag-correlation between the prevalence of obesity and diabetes and the consumption of B-vitamins (niacin, thiamin, and riboflavin) in the U.S., primarily due to mandatory food fortification [9]. Moreover, among the Bvitamins, niacin has been known to cause hepatic toxicity [32], insulin resistance [33,34], and oxidative stress $[29,35]$.

6) The metabolism of xenobiotics and ROS involves numerous enzymes. The polymorphisms in the genes of xenobiotic/drug-metabolizing enzymes and ROS-scavenging enzymes are expected to be involved in susceptibility to xenobiotic exposures and MetS. Indeed, evidence has shown that the gene polymorphisms of many of the enzymes, such as $N$-acetyltransferase 2 [36], superoxide dismutases [37], peroxiredoxins [38], glutathione $S$-transferase [39], and $\mathrm{NAD}(\mathrm{P}) \mathrm{H}$ oxidase [40], may play a crucial role in determining genetic susceptibility to metabolic disorders. Moreover, current research also shows correlations between polymorphisms in xenobiotic/drug-metabolizing enzymes and cancer susceptibility [41-43].

7) Dysfunctions of the organs that are responsible for the biotransformation and excretion of xenobiotics, such as the liver and kidney $[44,45]$, may increase the risk for MetS.

Recently, we hypothesize that MetS may be a consequence of chronic xenobiotic poisoning [2], which may involve a mechanism of xenobiotic-induced systemic tissue damage and subsequent decrease in cellular response to physiological signals (e.g., insensitive to insulin $[46,47])$, and methyl depletion and subsequent disturbance in numerous methylation-mediated reactions in the body (e.g., inhibition of catecholamine degradation [17]). All of the above evidence suggests that environmental/dietary factors and genetic factors in MetS may be, to some extent, a reflection of xenobiotic exposure and the efficiency of the body's xenobiotic-biotransforming/eliminating system and ROS-scavenging system (Figure 1). Therefore, it seems conceivable that any tissues/organs that contribute to the body's total antioxidant capacity might play some role in the development of MetS.

\section{The skin's antioxidant and excretory systems}

The skin provides both a mechanical and a chemical barrier between the body and surrounding environment. The chemical barrier is mediated by the skin's xenobiotic biotransformation system, ROS-scavenging system, and excretory system, all of which contribute to the body's total 


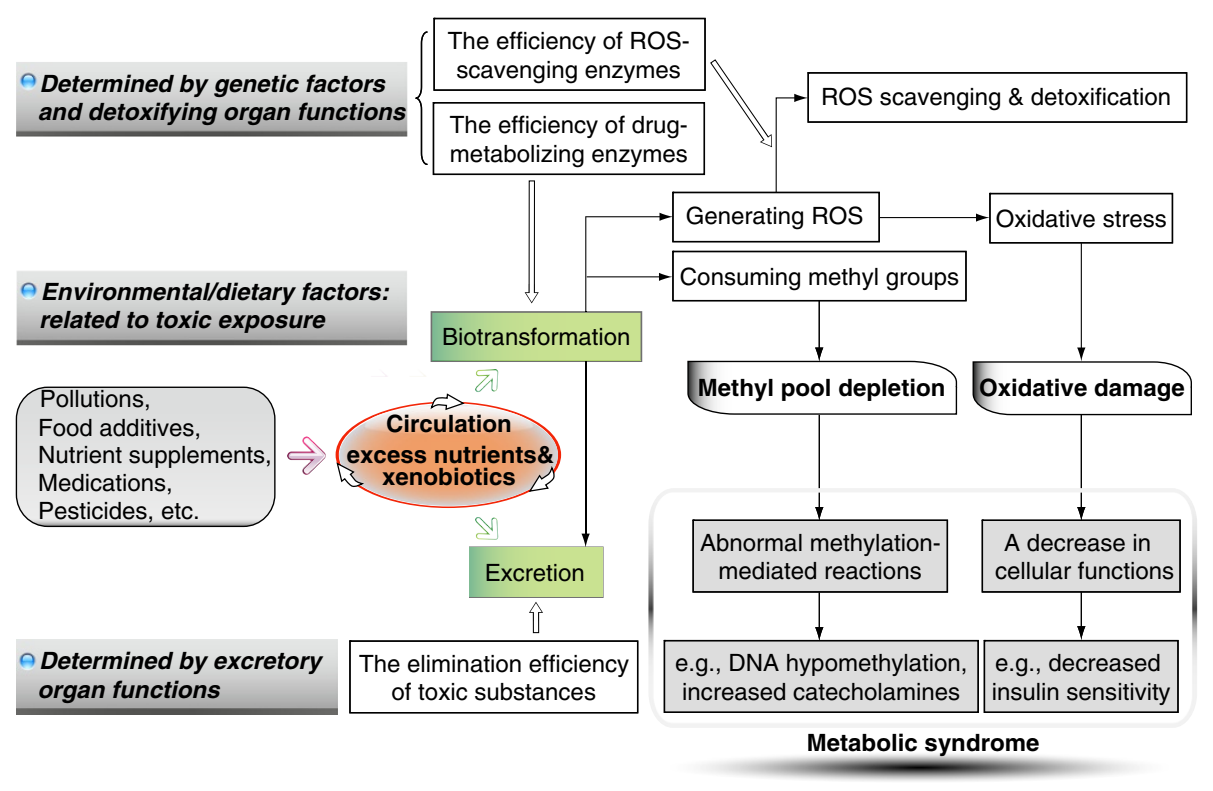

Figure 1 Possible link among environmental/dietary factors, genetic factors, oxidative stress, and aberrant methylation profile in MetS. Increased xenobiotic and synthetic-nutrient exposure may be the primary cause of MetS (See text and Ref. [2] for further details). ROS, reactive oxygen species.

antioxidant capacity. The following sections will discuss the skin's function and its role in MetS.

\section{Xenobiotic-metabolizing and ROS-scavenging systems of the skin}

Xenobiotic-metabolizing phase I and II enzymes are expressed differently in various tissues, determining the antioxidant capacity of a given tissue or organ. The skin expresses all known phase I and II enzymes, such as cytochrome P450 enzymes, flavin-dependent monooxygenase, monoamine oxidase, alcohol dehydrogenase, aldehyde dehydrogenase, NADP $(\mathrm{H})$ : quinone oxidoreductase, glutathione $S$-transferase, and catechol-O-methyhransferase $[14,48]$. The xenobiotic-metabolizing enzymes are induced in response to xenobiotic exposure [49,50]. Moreover, endogenous bioactive and toxic substances, such as catecholamines and steroids [48-51], are also substrates of phase I and II enzymes. Moreover, the skin is also equipped with an antioxidant system. For example, the skin expresses superoxide dismutase, catalase, and glutathione peroxidase, which can remove ROS [52].

The expression of both xenobiotic/drug-metabolizing and ROS-scavenging enzymes suggests that the skin may contribute to the body's total antioxidant defense. To test this hypothesis, our previous study investigated the role of the skin in the degradation of nicotinamide, a known insulin resistance inducer [34], by using a rat burn model, and found that rats underwent a $40 \%$ total body surface area burn injury exhibited a significantly higher baseline plasma $N^{1}$-methylnicotinamide (the toxic intermediate metabolite of nicotinamide) levels than shamtreated rats [29]. A nicotinamide $(100 \mathrm{mg} / \mathrm{kg}$ body weight, i.p.) plus glucose (2 $\mathrm{g} / \mathrm{kg}$ body weight, i.p.) loading test further revealed that the tolerance of burned rats to nicotinamide significantly decreased, which was characterized by high levels of plasma nicotinamide and $N^{1}$-methylnicotinamide associated with high levels of plasma $\mathrm{H}_{2} \mathrm{O}_{2}$ (a form of ROS) and insulin after coadministration of nicotinamide and glucose (unpublished data). These findings suggest that the skin may be a major component of the body's total antioxidant defense.

\section{Sweat-mediated elimination of toxic substances}

The skin also acts as an excretory organ. It is estimated that 3 to 4 million eccrine sweat glands which together roughly weigh the same as one kidney (i.e., $100 \mathrm{~g}$ ) are distributed over almost the entire human body surface. An individual can perspire as much as several liters per hour and approximately 10 liters per day [11]. Watersoluble exogenous and endogenous toxic/bioactive substances, such as metals [11], drugs [10], cytokines [53], and steroids [54], can be eliminated in the sweat. Genuis et al. [55] analyzed for approximately 120 various compounds, including toxic elements, and found that many toxic elements appeared to be preferentially excreted through sweat. It is worth noting that some 
xenobiotics that are rarely excreted in the urine without being metabolized, but can be excreted in the sweat. For example, excess nicotinamide cannot be eliminated through urine because of its reabsorption by the renal tubules, but it can be effectively excreted by the sweat gland [29].

Xenobiotic metabolism may produce toxic intermediate products and ROS [6-8,16,29]. Therefore, sweatinginduced elimination of xenobiotics is expected to reduce the production of toxic intermediate products and thus prevent oxidative stress. Indeed, our previous study found that the levels of nicotinamide but not its toxic intermediate metabolite $N^{1}$-methylnicotinamide in the sweat significantly increased after nicotinamide loading [29]. Masuda et al. have also observed that sauna, which increases the skin temperature and induces sweating, can protect against oxidative stress [56]. Moreover, sauna has been found to alleviate symptoms of intoxication $[57,58]$ and improve lifestyle-related diseases [59-61]. The beneficial effect of saunas is thought to be related sweatmediated elimination of toxic substances from the body [61]. Although not proved, increased skin temperatureinduced changes in the activity of xenobiotic- and ROS-metabolizing enzymes may also contribute to the beneficial effect of sauna. Thus, it appears that sweating might be an important antioxidant mechanism, especially for individuals who have a genetic enzymatic defect in dealing with xenobiotics and ROS.

\section{Sebum-mediated elimination of excess lipids and cholesterol}

It is known that there are two major pathways for the elimination of water-soluble compounds (including excessive nutrients) from the circulation: urine and sweat. As for the elimination of excessive circulating lipids and fat-soluble substances, sebum secretion may be an important pathway, though this factor has received little attention in the investigation of lipid homeostasis.

Sebaceous gland, which produces sebum, is found throughout the human body except on the palms of the hands and soles of the feet. Sebum is composed of triglycerides, fatty acids, cholesterol, squalene, and wax esters. The major component of human sebum is triglycerides and fatty acids (57\%), which is much higher than that of other species, such as rodents and rabbit (their triglycerides and free fatty acids $<10 \%)$ [15]. Studies have shown that the production of sebum is linked to diet, for example, caloric deprivation decreases the production of sebum [62,63], whereas a high fat diet significantly increases it [64]. Since an increase in energy intake mainly increases the excretion of triglycerides and cholesterol and its esters in sebum, but not of squalene $[62,63]$, it appears that the major function of sebum secretion may be to eliminate excessive lipids and cholesterol from the body, and thus play a role in maintaining lipid and cholesterol homeostasis. This notion is supported by the observation that inhibition of sebum secretion by isotretinoin significantly increases plasma triglyceride and cholesterol levels [65,66].

\section{Factors affecting skin antioxidant and excretion efficiencies}

The skin function is affected by external factors, such as lifestyles and working conditions [67]. Among known factors, temperature may be probably the most important. The optimum temperature for human enzymes, including skin biotransformation enzymes $[12,68]$, is about $37{ }^{\circ} \mathrm{C}$. The activity of enzymes in internal organs is rather stable, because the core temperature of the body is maintained at a constant level close to $37{ }^{\circ} \mathrm{C}$; but the activity of skin enzymes changes with the skin temperature, which is considerably affected by ambient temperature [69]. Moreover, the activity of sweat glands is also conditional. During heat exposure, increases in body temperature trigger cutaneous vasodilation and sweating. With hyperthermia in humans, blood flow to the skin can increase from approximately $250 \mathrm{~mL} / \mathrm{min}$ in thermoneutral environments to as much as 6 to $8 \mathrm{~L} / \mathrm{min}$ or $60 \%$ of the cardiac output [70]. A heat exposure-induced increase in blood flow to the skin and the skin temperature could, in theory, increase: 1 ) the activity of skin enzymes; 2) the probability of enzymes catching toxic substances in the circulation; 3 ) sweat-mediated elimination of toxic substances, because water-soluble toxic substances can be excreted in sweat $[10,11,53,54]$; and 4) sebum-mediated elimination of circulating lipids and cholesterol, because sebum secretion is temperature-dependent [71-73]. All of these changes during heat exposure strengthen the body's antioxidant defense and increase the excretion of circulating lipids and cholesterol. On the contrary, upon exposure to cold environments, blood flow to the skin decreases via cutaneous vasoconstriction [70], which results in a decrease in the functions of the skin. Obviously, changes in skin function might lead to changes in the body's total antioxidant capacity.

\section{Sedentary lifestyles and skin's antioxidant efficiency}

A sedentary lifestyle is associated with an increased risk of MetS $[74,75]$, which is usually attributed to decreased energy expenditure. Indeed, moderate-to-vigorous physical activity, which increases energy expenditure, may produce beneficial effects [76-78]. However, recently, Thorp and colleagues [74], after having reviewed forty-eight studies published between 1996 and January 2011 on sedentary behaviors and subsequent health outcomes in adults, concluded that the effect of sedentary behavior on health outcomes may be independent of 
physical activity. Moreover, Sisson et al. [79] examined leisure time sedentary behavior and usual occupational/ domestic activity and their relationship with MetS and individual cardiovascular disease risk factors, and also found that usual occupational/domestic activity was not strongly associated with MetS or CVD risk factors, although their data also showed an association between sedentary behavior and MetS. It seems that the effect of sedentary lifestyles on MetS may be not just a matter of decreased energy expenditure.

The body usually does not sweat at room temperature (i.e., living a sedentary lifestyle), which may reduce sweatmediated elimination of toxic substances and excess nutrients from the body. In contrast, sweating-inducing factors, such as sauna and exercise, can facilitate the elimination, as discussed above. Unfortunately, in most studies on sedentary lifestyle and exercise and their relationship with MetS and related diseases, the accompanying changes in skin contribution to the body's antioxidant capacity are usually neglected.

It might be worth noting that exercise might be a double-edged sword, for it also increases the generation of ROS and subsequent risk of oxidative stress [80]. Moreover, not everyone is healthy enough for exercise that induces sweating. In contrast, sweating induced by exposure to a hot environment (natural sweating) could not only effectively eliminate toxic substances from the body, but it also avoid the generation of ROS through muscle activity. Theoretically, natural sweating might be more effective and practical than exercise-induced sweating in the prevention and treatment of MetS.
In addition, Pearson and Biddle [75], after having reviewed fifty-three relevant studies, concluded that sedentary behavior is clearly associated with unhealthy diet including lower fruit and vegetable consumption and higher consumption of snacks and fast foods. Because snacks and fast foods, which are used as a fortification vehicle [81], have much higher concentrations of synthetic vitamins than other food items (e.g., the amount of niacin in ready-to-eat cereals is $76 \mathrm{mg} /$ pound in 1974-2000 according to the fortification recommendations [81]), high consumption of these foods may lead to an excessive synthetic-vitamin intake, whereas sedentary lifestyle may decrease skin-mediated elimination of toxic substances and excess nutrients, as discussed above. The combination of these two factors might play a major role in the development of MetS.

\section{The skin function and obesity}

Obesity is the result of a chronic excess energy intake. As shown in Figure 2, excess dietary carbohydrates can be converted either into liver and muscle glycogen [82] or into fat in adipose tissue [83], while excess dietary fat, besides being stored as body fat, can also be eliminated in the form of sebum. In the circumstances of chronic excess energy intake and inhibition of sebum secretion, excess lipids are only stored as adipose tissue, whereas excess cholesterol can accumulate in the arterial wall, which has long been recognized [84]. As a result, obesity and atherosclerosis may occur. This notion is supported not only by the observations that there is usually low sebum secretion [71-73] but high blood lipid levels




[85-88] and weight gain $[89,90]$ in winter, but also by the findings that medication-induced inhibition of sebum secretion increases the levels of circulating lipids and cholesterol, and, consequently, the risk of dyslipidemia and MetS [65,66,91].

Studies have revealed that: (1) the driver for the global obesity epidemic may be in the food system [4], (2) food insecurity leads to obesity [92,93], (3) there is a correlation between the epidemic of obesity and diabetes and increased exposure to synthetic B-vitamins (niacin, thiamin, and riboflavin) due to food fortification (Figure 3), (4) obese and overweight persons have uncontrollable eating [94,95], and (5) evidence suggests that oxidative stress caused dysregulated production of inflammationrelated adipocytokines (fat-derived hormones) [96-98]. We therefore suspected that xenobiotics might be related to the etiology of uncontrollable eating in obesity. Our previous work tested this hypothesis by conducting oral glucose tolerance tests with or without the presence of nicotinamide in the same healthy subjects, and, as expected, found that co-loading of glucose and nicotinamide triggered a hypoglycemic reaction (i.e. low blood glucose levels with hunger feeling) in the later phase of the loading test $(3 \mathrm{~h}$ ) due to increased ROS generation and insulin resistance occurred in the earlier phase [35]. This finding provides evidence, for the first time, that dietary xenobiotics may play a primary causal role in uncontrolled eating. Sweating can excrete toxic substances $[10,11,55]$, including excess nicotinamide [29]. Thus, sweating-mediated toxin elimination is expected to prevent eating disorders. In agreement with this notion, Biro et al. found that sauna could effectively reduce not only body weight and body fat but also the abnormal eating behavior in obesity [59]. All of the above evidence suggests that the skin antioxidant and excretory functions may play a role in obesity.

\section{The skin function and seasonal variations of metabolic syndrome}

Metabolic disorders share two common features: 1) regional differences in their prevalence and 2) seasonal variations in their symptoms and signs. The prevalence of MetS and related diseases in high-latitude regions is higher than that in low-latitude regions; for example, the prevalence of hypertension, obesity and cardiovascular disease is higher in North China than in South China [99-101]. Blood pressure also shows seasonal fluctuations (higher in cold season) [85,102]. Kamezaki et al. found that the prevalence rates of MetS are higher in winter than in summer [85]. One of the most compelling factors contributing to the seasonal and regional variations may be temperature. Indeed, two recent studies after threeyear observations have found a negative correlation between blood pressure and outside temperature $[103,104]$. Kimura and colleagues found that a $1{ }^{\circ} \mathrm{C}$ decrease in the mean outdoor temperature was associated with rises of $0.43 \mathrm{mmHg}$ in systolic blood pressure and $0.29 \mathrm{mmHg}$ in diastolic blood pressure [103]. Hozawa et al. reported that when the outside temperature was $\geq$ $10{ }^{\circ} \mathrm{C}, 1{ }^{\circ} \mathrm{C}$ increment of outside temperature corresponded to 0.40 and $0.28 \mathrm{mmHg}$ decrease of systolic blood pressure and diastolic blood pressure [104]. Thus, it is possible that the skin may mediate the association between blood
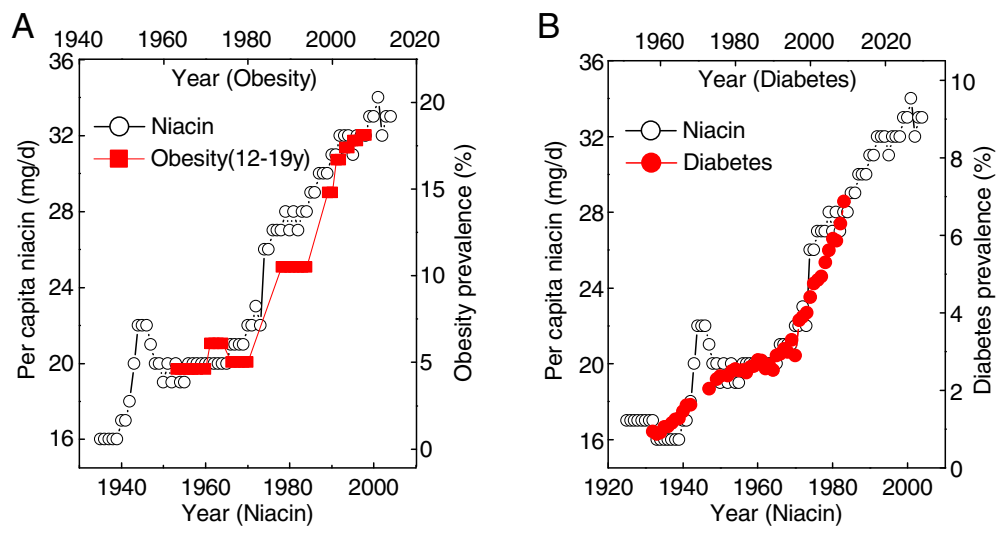

Figure 3 Trends in U.S. per capita niacin consumption and the prevalence of obesity and diabetes. The prevalence of obesity (A) and diabetes (B) increased in parallel with the increase in U.S. per capita niacin consumption with a lag of 10 years and 26 years, respectively (see Ref. [9,35] for detail). The sharp increase in niacin consumption in 1940s and 1974 is due to the implementation of mandatory grain fortification and the update of fortification standards, respectively. The data on the prevalence of obesity and diabetes are from the U.S. Centers for Disease Control and Prevention (http://www.cdc.gov/nchs/data/hestat/obesity_child_07_08/obesity_child_07_08.htm; and http://www.cdc.gov/diabetes/ statistics/slides/long_term_trends.pdf. Accessed March 24, 2012). The data on U.S. per capita consumption of niacin is from Economic Research Service: Nutrient Availability Spreadsheets, (http://www.ers.usda.gov/data/foodconsumption/NutrientAvaillndex.htm. Accessed March 24, 2012). 
pressure fluctuations and ambient temperature, because the skin is more vulnerable to environmental temperature than other organs in the body. Although there currently is no systematic study on this issue, several lines of evidence suggest that the seasonal variation of MetS may involve seasonal fluctuations in skin-mediated elimination, excretion and biotransformation of toxic substances and excess nutrients, such as lipids, catecholamines, and niacin.

Numerous studies have shown that there is a substantial increase in blood cholesterol level in winter [85-88], while the data on the seasonal variation of serum triglycerides appear to be inconsistent $[85,88]$. Low ambient temperature decreases the elimination of triglycerides and cholesterol due to a reduction in sebum secretion [71-73], which is expected to raise the level of both triglycerides and cholesterol in the blood. However, excess triglycerides can be stored as fat in adipose tissue (indeed, body mass may increase in winter $[89,90])$, while excess cholesterol would likely be left in the blood streams in decreased sebum-secretion condition. As a result, the serum cholesterol level is elevated in winter. This interpretation is supported by the observation that inhibition of sebum secretion by isotretinoin may lead to an increase in both serum triglyceride and cholesterol levels [65,66,91]. Unlike the effect of cold exposure, which may be regional and dependent upon clothing condition, the effect of isotretinoin should be an overall sustained inhibition of the sebaceous glands in the body. This may explain the increase in serum triglyceride level during isotretinoin treatment.

Catecholamines, which mediate the cardiovascular effects of the adrenergic nervous system, are degraded/ inactivated by monoamine oxidase and catechol-Omethyhransferase [105]. An increase in the degradation of catecholamines generates more end metabolites (i.e., homovanillic acid and vanillylmandelic acid), while a decrease in the degradation might result in an increase in the levels of circulating catecholamines [17]. The skin expresses monoamine oxidase and catechol-Omethyhransferase [48], and thus might play a role in the inactivation of circulating catecholamines. Studies have shown that the blood concentrations of the end metabolites of catecholamines are lower in winter than in summer [106], whereas the levels of plasma norepinephrine and epinephrine are higher in winter than in summer [107]. These observations suggest a decrease in the degradation of catecholamines in winter. It seems that there is a negative relationship between the degradation rate of catecholamines and the seasonal fluctuations of blood pressure. Given that 1) seasonal changes may change the skin temperature and subsequent the activities of cutaneous catecholamine-degrading enzymes, but do not change the core temperature and the enzyme activity in internal organs; and 2) water-soluble free amino acids and neurotransmitters can be excreted in sweat [11], it appears that the seasonal variation in circulating catecholamines might be related to the seasonal variation in skin functions.

Niacin is precursor of NAD and NADP, which are coenzymes in numerous essential redox reactions in cellular metabolism. Niacin deficiency causes pellagra, while excessive nicotinamide may increase the risk for MetS, for it induces oxidative stress and insulin resistance [29,33-35] and disturb the degradation of catecholamines [17]. Pellagra occurs mostly in the summer months (i.e., a season facilitating sweating) in rural poor people who consume a niacin-poor diet [108], while MetS is worse in winter (i.e., a season inhibiting sweating) [85], and commonly occurs in people who consume a niacin-fortified diet [9]. Since niacin can be excreted in the sweat [29], these phenomena may involve sweating-mediated niacin elimination, but further studies needed to confirm this.

\section{Skin diseases and metabolic syndrome}

Numerous studies have shown that a variety of skin disorders are frequently associated with metabolic disorders. Based on available evidence, it seems that the associations might involve skin antioxidant and excretory functions.

\section{Acanthosis nigricans}

Acanthosis nigricans, a hyperplastic skin lesion, is associated with insulin resistance, obesity, MetS, and type 2 diabetes $[109,110]$. The following evidence suggests that acanthosis nigricans might be linked to skin-mediated xenobiotic detoxification:

- Long-term exposure to xenobiotics, such as niacin, glucocorticoids, and oral contraceptives, increases the risk for both acanthosis nigricans [109] and MetS [111].

- There has been a significant increase in xenobiotic exposure in general population due to food additives and especially mandatory implementation of synthetic vitamin fortification [9].

- The prevalence of obesity, which is closely associated with acanthosis nigricans [109], is positively correlated with niacin consumption $[9,35]$.

- Physical activity, which can increase the sweaty excretion of xenobiotics, reduces the risk of acanthosis nigricans [112].

Since xenobiotics induce xenobiotic-metabolizing enzymes [49,50] and cell proliferation [113,114], it appears that increased cell proliferation in acanthosis nigricans might be a compensatory mechanism in response to chronic high xenobiotic exposure, but further studies are needed to test this hypothesis. 


\section{Acne}

Acne, a common skin condition, is closely related to increased sebum production [115]. As mentioned above, increased sebum secretion may be helpful to remove excess lipids and cholesterol from the body. Therefore, in theory, inhibition of sebum secretion would increase the accumulation of lipids and cholesterol in the body. In fact, numerous studies have found that long-term medication-induced inhibition of sebum secretion can lead to significant increases in the levels of lipids and cholesterol in the circulation, and consequently increase the risk of MetS [91] and atherosclerosis [65,66]. Given that sebum secretion is positively related to caloric intake $[62,63]$, it seems that increased sebum secretion, although increasing the risk of acne, may be a protective mechanism in response to excess energy intake. Indeed, in a retrospective follow-up study of 11,232 men who attended Glasgow University between 1948 and 1968 and whose mortality was traced into 2004, the authors found that participants who reported having acne during adolescence had a significantly lower risk of death from coronary heart disease [116]. The analysis of the available literature suggests that the best solution for solving the acne problems may be to reduce appetite and total energy intake, rather than to inhibit sebum secretion with medications.

\section{Burns}

Severe burns covering $>40 \%$ of the total body surface area lead to profound metabolic changes. Insulin resistance is one of the most prominent post-burn metabolic abnormalities. Burn-induced insulin resistance, unlike other trauma-induced temporary insulin resistance, is a long-lasting phenomenon, and it still persists after burn wounds have already healed [117]. Obviously, severe skin burns cause a permanent decrease in or loss of the biotransformation, detoxification, antioxidant, and excretory functions in the burned area, which may cause a permanent decrease in the body's total antioxidant capacity due to decreased skin contribution. If this were the case, it is expected that there would still be an accumulation of toxic and bioactive substances in the circulation after burn injuries have healed. Indeed, a recently published study has found that healed severe burns are still associated with an elevation in circulating cortisol, catecholamines, and cytokines, all of which are insulin
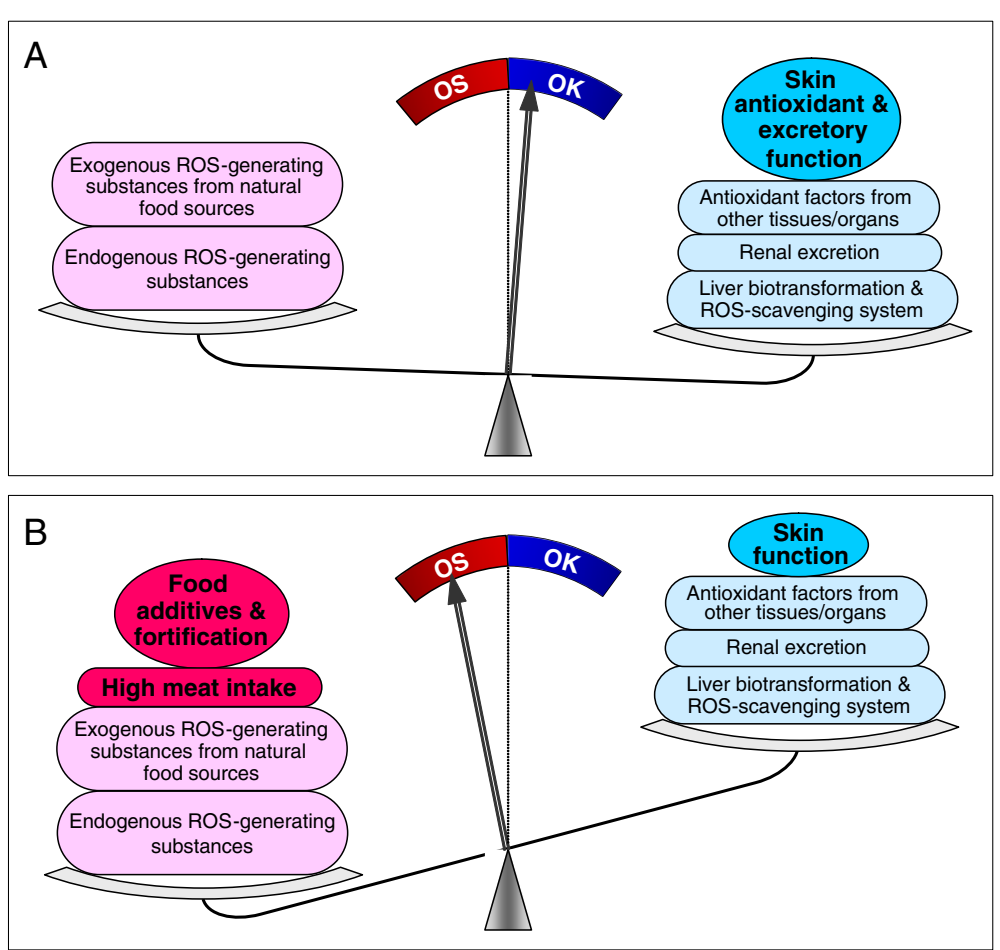

Figure 4 Factors affecting the balance between ROS production and scavenging. A, In traditional lifestyles, ROS are derived from the metabolism of endogenous and exogenous (i.e., natural dietary) substances. The skin, especially its sweat glands, may play an important antioxidant role. B, In modern lifestyles, dietary xenobiotics have significantly increased, while the skin functions, especially sweat-mediated excretion, is decreased due to sedentary lifestyles. As a result, an imbalance between ROS production and the body's antioxidant defense system takes place. OK, antioxidant defense capacity > ROS production; OS, oxidative stress. 
resistance-inducing factors [118]. Therefore, it appears that post-burn metabolic disorders might be due to a permanent decrease in the skin-contribution to the body's antioxidant capacity.

\section{Conclusion and perspectives}

The imbalance between ROS generation and the body total antioxidant defense system in MetS may be a consequence of the combination of excessive xenobiotic exposure (including fortification-induced high synthetic-vitamin exposure) and decreased detoxification/elimination of xenobiotics due to lifestyle and genetic factors. The skin's antioxidant and excretory function may be one of the major components of the body's antioxidant defense system and play an important role in anti-MetS (Figure 4).

The physiological functions of skin might be probably more complex than expected. In this review we focused solely on the possible relationship between the skin detoxification and excretory functions and MetS. The skin, without doubt, has some other important functions, for example, it is involved in the metabolism of many endogenous bioactive substances and some vitamins. Although the basic functions of skin have been well documented, the role of skin in systemic metabolic disorders is far from clear. Therefore, further studies are required for deep understanding of the role of the skin in the development of MetS.

\section{Competing interests}

The authors declare that they have no competing interests.

\section{Acknowledgements}

This study was supported by National Natural Science Foundation of China (No. 31140036) and 973 program (2011CB503900).

\section{Author details \\ 'Department of Physiology, Medical College, Dalian University, Dalian, 116622, China. ${ }^{2}$ Department of Physiology, China Medical University, Shenyang, 110001, China. ${ }^{3}$ Section of Cell Signaling, Okazaki Institute for Integrative Bioscience, National Institutes of Natural Sciences, Okazaki, 444-8787, Japan. ${ }^{4}$ Department of Physiology and Pathophysiology, Institute of Basic Medical Sciences, Chinese Academy of Medical Sciences, School of Basic Medicine Peking Union Medical College, Beijing, 100005, China.}

\section{Authors' contributions}

SSZ conceived and drafted the manuscript and the figures, DL participated in the preparation of the figures, $\mathrm{DL}$ and $\mathrm{YMZ}$ contributed to the acquisition of data and revised the manuscript, JMC reviewed the manuscript critically. All authors read and approved the final manuscript.

Received: 20 January 2012 Accepted: 26 April 2012

Published: 26 April 2012

\section{References}

1. Roberts CK, Sindhu KK: Oxidative stress and metabolic syndrome. Life Sci 2009, 84:705-712.

2. Zhou SS, Zhou YM, Li D, Lun YZ: Dietary methyl-consuming compounds and metabolic syndrome. Hypertens Res 2011, 34:1239-1245.

3. Wong ND: Metabolic syndrome: cardiovascular risk assessment and management. Am J Cardiovasc Drugs 2007, 7:259-272.

4. Swinburn BA, Sacks G, Hall KD, McPherson K, Finegood DT, Moodie ML, Gortmaker SL: The global obesity pandemic: shaped by global drivers and local environments. Lancet 2011, 378:804-814

5. Grattagliano I, Palmieri VO, Portincasa P, Moschetta A, Palasciano G: Oxidative stress-induced risk factors associated with the metabolic syndrome: a unifying hypothesis. J Nutr Biochem 2008, 19:491-504.

6. Mena S, Ortega A, Estrela JM: Oxidative stress in environmental-induced carcinogenesis. Mutat Res 2009, 674:36-44.

7. Valko M, Morris H, Cronin MT: Metals, toxicity and oxidative stress. Curr Med Chem 2005, 12:1161-1208.

8. Johnson $\mathrm{CH}$, Patterson AD, Idle JR, Gonzalez FJ: Xenobiotic metabolomics: major impact on the metabolome. Annu Rev Pharmacol Toxicol 2012, 52:37-56.

9. Zhou SS, Li D, Zhou YM, Sun WP, Liu QG: B-vitamin consumption and the prevalence of diabetes and obesity among the US adults: population based ecological study. BMC Public Health 2010, 10:746.

10. Johnson HL, Maibach HI: Drug excretion in human eccrine sweat. J Invest Dermatol 1971, 56:182-188.

11. Sato K: The physiology, pharmacology, and biochemistry of the eccrine sweat gland. Rev Physiol Biochem Pharmacol 1977, 79:51-131.

12. Smallridge RC, Gamblin GT, Eil C: Angiotensin-converting enzyme: characteristics in human skin fibroblasts. Metabolism 1986, 35:899-904.

13. Arck PC, Slominski A, Theoharides TC, Peters EM, Paus R: Neuroimmunology of stress: skin takes center stage. J Invest Dermatol 2006, 126:1697-1704.

14. Oesch F, Fabian E, Oesch-Bartlomowicz B, Werner C, Landsiedel R: Drug-metabolizing enzymes in the skin of man, rat, and pig. Drug Metab Rev 2007, 39:659-698.

15. Smith KR, Thiboutot DM: Sebaceous gland lipids: friend or foe?. J Lipid Res 2008, 49:271-281.

16. Xu C, Li CY, Kong AN: Induction of phase I, II and III drug metabolism/ transport by xenobiotics. Arch Pharm Res 2005, 28:249-268.

17. Sun WP, Li D, Lun YZ, Gong XJ, Sun SX, Guo M, Jing LX, Zhang LB, Xiao FC, Zhou SS: Excess nicotinamide inhibits methylation-mediated degradation of catecholamines in normotensives and hypertensives. Hypertens Res 2012, 35:180-185.

18. Mancia G, Bousquet P, Elghozi JL, Esler M, Grassi G, Julius S, Reid J, Van Zwieten PA: The sympathetic nervous system and the metabolic syndrome. J Hypertens 2007, 25:909-920.

19. Wang SL, Chang FH, Liou SH, Wang HJ, Li WF, Hsieh DP: Inorganic arsenic exposure and its relation to metabolic syndrome in an industrial area of Taiwan. Environ Int 2007, 33:805-811.

20. Chen H, Li S, Liu J, Diwan BA, Barrett JC, Waalkes MP: Chronic inorganic arsenic exposure induces hepatic global and individual gene hypomethylation: implications for arsenic hepatocarcinogenesis. Carcinogenesis 2004, 25:1779-1786.

21. Nohara K, Baba T, Murai H, Kobayashi Y, Suzuki T, Tateishi Y, Matsumoto M, Nishimura N, Sano T: Global DNA methylation in the mouse liver is affected by methyl deficiency and arsenic in a sex-dependent manner. Arch Toxicol 2011, 85:653-661.

22. Lee DH, Lee IK, Porta M, Steffes M, Jacobs DR Jr: Relationship between serum concentrations of persistent organic pollutants and the prevalence of metabolic syndrome among non-diabetic adults: results from the National Health and Nutrition Examination Survey 1999-2002. Diabetologia 2007, 50:1841-1851.

23. Lim S, Cho YM, Park KS, Lee HK: Persistent organic pollutants, mitochondrial dysfunction, and metabolic syndrome. Ann N Y Acad Sci 2010, 1201:166-176

24. Dirinck E, Jorens PG, Covaci A, Geens T, Roosens L, Neels H, Mertens I, Van Gaal L: Obesity and persistent organic pollutants: possible obesogenic effect of organochlorine pesticides and polychlorinated biphenyls. Obesity (Silver Spring) 2011, 19:709-714.

25. Hasnain M, Fredrickson SK, Vieweg WV, Pandurangi AK: Metabolic syndrome associated with schizophrenia and atypical antipsychotics. Curr Diab Rep 2010, 10:209-216.

26. Lee NY, Kim SH, Cho B, Lee YJ, Chang JS, Kang UG, Kim YS, Ahn YM: Patients taking medications for bipolar disorder are more prone to metabolic syndrome than Korea's general population. Prog Neuropsychopharmacol Biol Psychiatry 2010, 34:1243-1249.

27. Redig AJ, Munshi HG: Care of the cancer survivor: metabolic syndrome after hormone-modifying therapy. Am J Med 2010, 123(87):e1-87. e6.

28. Craig SA: Betaine in human nutrition. Am J Clin Nutr 2004, 80:539-549.

29. Zhou SS, Li D, Sun WP, Guo M, Lun YZ, Zhou YM, Xiao FC, Jing LX, Sun SX, Zhang LB, Luo N, Bian FN, Zou W, Dong LB, Zhao ZG, Li SF, Gong XJ, Yu ZG, Sun $C B$, Zheng $C L$, Jiang DJ, Li ZN: Nicotinamide overload may play a role in the 
development of type 2 diabetes. World J Gastroenterol 2009, 15:5674-5684.

30. Sakaki T, Kagawa N, Yamamoto K, Inouye K: Metabolism of vitamin D3 by cytochromes P450. Front Biosci 2005, 10:119-134.

31. Landes N, Birringer M, Brigelius-Flohé R: Homologous metabolic and gene activating routes for vitamins E and K. Mol Aspects Med 2003, 24:337-344

32. Rader JI, Calvert RJ, Hathcock JN: Hepatic toxicity of unmodified and time-release preparations of niacin. Am J Med 1992, 92:77-81.

33. Kahn SE, Beard JC, Schwartz MW, Ward WK, Ding HL, Bergman RN, Taborsky GJ Jr, Porte D Jr: Increased beta-cell secretory capacity as mechanism for islet adaptation to nicotinic acid-induced insulin resistance. Diabetes 1989, 38:562-568.

34. Greenbaum CJ, Kahn SE, Palmer JP: Nicotinamide's effects on glucose metabolism in subjects at risk for IDDM. Diabetes 1996, 45:1631-1634.

35. Li D, Sun WP, Zhou YM, Liu QG, Zhou SS, Luo N, Bian FN, Zhao ZG, Guo M: Chronic niacin overload may be involved in the increased prevalence of obesity in US children. World J Gastroenterol 2010, 16:2378-2387.

36. Semiz S, Dujic T, Ostanek B, Velija-Asimi Z, Prnjavorac B, Bego T, Malenica M, Mlinar B, Heljic B, Marc J, Causevic A: Association of NAT2 polymorphisms with type 2 diabetes in a population from Bosnia and Herzegovina. Arch Med Res 2011, 42:311-317.

37. Flekac M, Skrha J, Hilgertova J, Lacinova Z, Jarolimkova M: Gene polymorphisms of superoxide dismutases and catalase in diabetes mellitus. BMC Med Genet 2008, 9:30.

38. Hiroi M, Nagahara Y, Miyauchi R, Misaki Y, Goda T, Kasezawa N, Sasaki S, Yamakawa-Kobayashi $\mathrm{K}$ : The combination of genetic variations in the PRDX3 gene and dietary fat intake contribute to obesity risk. Obesity (Silver Spring) 2011, 19:882-887.

39. Bid HK, Konwar R, Saxena M, Chaudhari P, Agrawal CG, Banerjee M: Association of glutathione S-transferase (GSTM1, T1 and P1) gene polymorphisms with type 2 diabetes mellitus in north Indian population. J Postgrad Med 2010, 56:176-181.

40. Ge J, Ding Z, Song Y, Wang F: Smoking dose modifies the association between C242T polymorphism and prevalence of metabolic syndrome in a chinese population. PLoS One 2012, 7:e31926.

41. Ouerhani S, Nefzi MA, Menif S, Safra I, Douzi K, Fouzai C, Ben Ghorbel G, Ben Bahria I, Ben Ammar Elgaaied A, Abbes S: Influence of genetic polymorphisms of xenobiotic metabolizing enzymes on the risk of developing leukemia in a Tunisian population. Bull Cancer 2011, 98:95-106

42. Li X, Hu Z, Qu X, Zhu J, Li L, Ring BZ, Su L: Putative EPHX1 enzyme activity is related with risk of lung and upper aerodigestive tract cancers: a comprehensive meta-analysis. PLoS One 2011, 6:e14749.

43. Sharma R, Ahuja M, Panda NK, Khullar M: Interactions among genetic variants in tobacco metabolizing genes and smoking are associated with head and neck cancer susceptibility in North Indians. DNA Cell Biol 2011, 30:611-616

44. Watanabe S, Yaginuma R, Ikejima K, Miyazaki A: Liver diseases and metabolic syndrome. J Gastroenterol 2008, 43:509-518.

45. Peralta CA, Kurella M, Lo JC, Chertow GM: The metabolic syndrome and chronic kidney disease. Curr Opin Nephrol Hypertens 2006, 15:361-365.

46. Houstis N, Rosen ED, Lander ES: Reactive oxygen species have a causal role in multiple forms of insulin resistance. Nature 2006, 440:944-948.

47. Henriksen EJ, Diamond-Stanic MK, Marchionne EM: Oxidative stress and the etiology of insulin resistance and type 2 diabetes. Free Radic Biol Med 2011, 51:993-999.

48. Moeller $\mathrm{H}$ : On metabolism of noradrenaline in the skin: activity of catechol-O-methyl transferase and monoamine oxidase. Acta Derm Venereol 1963, 43:552-555.

49. Bock KW, Lipp HP, Bock-Hennig BS: Induction of drug-metabolizing enzymes by xenobiotics. Xenobiotica 1990, 20:1101-1111.

50. Ahmad N, Mukhtar H: Cytochrome p450: a target for drug development for skin diseases. J Invest Dermatol 2004, 123:417-425.

51. Crooks PA, Breakefield XO, Sulens $\mathrm{CH}$, Castiglione CM, Coward JK: Extensive conjugation of dopamine (3,4-dihydroxyphenethylamine) metabolites in cultured human skin fibroblasts and rat hepatoma cells. Biochem J 1978, 176:187-196.

52. Steiling H, Munz B, Werner S, Brauchle M: Different types of ROS-scavenging enzymes are expressed during cutaneous wound repair. Exp Cell Res 1999, 247:484-494.

53. Cizza G, Marques AH, Eskandari F, Christie IC, Torvik S, Silverman MN, Phillips TM, Sternberg EM, POWER Study Group: Elevated neuroimmune biomarkers in sweat patches and plasma of premenopausal women with major depressive disorder in remission: the POWER study. Biol Psychiatry 2008, 64:907-911.

54. Takemura T, Wertz PW, Sato K: Free fatty acids and sterols in human eccrine sweat. Br J Dermatol 1989, 120:43-47.

55. Genuis SJ, Birkholz D, Rodushkin I, Beesoon S: Blood, urine, and sweat (BUS) study: monitoring and elimination of bioaccumulated toxic elements. Arch Environ Contam Toxicol 2011, 61:344-357.

56. Masuda A, Miyata M, Kihara T, Minagoe S, Tei C: Repeated sauna therapy reduces urinary 8-epi-prostaglandin F2 alpha. Jpn Heart J 2004, 45:297-303.

57. Krop J: Chemical sensitivity after intoxication at work with solvents: response to sauna therapy. J Altern Complement Med 1998, 4:77-86.

58. Ross GH, Sternquist MC: Methamphetamine exposure and chronic illness in police officers: significant improvement with sauna-based detoxification therapy. Toxicol Ind Health 2011, doi: 10.1177/ 0748233711425070.

59. Biro S, Masuda A, Kihara T, Tei C: Clinical implications of thermal therapy in lifestyle-related diseases. Exp Biol Med (Maywood) 2003, 228:1245-1249.

60. Beever R: Far-infrared saunas for treatment of cardiovascular risk factors: summary of published evidence. Can Fam Physician 2009, 55:691-696.

61. Crinnion WJ: Sauna as a valuable clinical tool for cardiovascular, autoimmune, toxicant-induced and other chronic health problems. Altern Med Rev 2011, 16:215-225.

62. Pochi PE, Downing DT, Strauss JS: Sebaceous gland response in man to prolonged total caloric deprivation. J Invest Dermatol 1970, 55:303-309.

63. Downing DT, Strauss JS, Pochi PE: Changes in skin surface lipid composition induced by severe caloric restriction in man. Am J Clin Nutr 1972, 25:267-365.

64. Wilkinson DI: Psoriasis and dietary fat: the fatty acid composition of surface and scale (ether-soluble) lipids. J Invest Dermatol 1966, 47:185-192.

65. Zech LA, Gross EG, Peck GL, Brewer HB: Changes in plasma cholesterol and triglyceride levels after treatment with oral isotretinoin. A prospective study. Arch Dermatol 1983, 119:987-993.

66. Bershad S, Rubinstein A, Paterniti JR, Le NA, Poliak SC, Heller B, Ginsberg HN, Fleischmajer R, Brown W: Changes in plasma lipids and lipoproteins during isotretinoin therapy for acne. N Engl J Med 1985, 313:981-985.

67. Kleesz P, Darlenski R, Fluhr JW: Full-body skin mapping for six biophysical parameters: baseline values at 16 anatomical sites in 125 human subjects. Skin Pharmacol Physiol 2012, 25:25-33.

68. Francis D, Greaves MW, Yamamoto S: Enzymatic histamine degradation by human skin. Br J Pharmacol 1977, 60:583-587.

69. Bedford T: Skin Temperature in relation to the warmth of the environment. J Hyg (Lond) 1935, 35:307-317.

70. Charkoudian N: Skin blood flow in adult human thermoregulation: how it works, when it does not, and why. Mayo Clin Proc 2003, 78:603-612.

71. Piérard-Franchimont C, Piérard GE, Kligman A: Seasonal modulation of sebum excretion. Dermatologica 1990, 181:21-22.

72. Qiu H, Long X, Ye JC, Hou J, Senee J, Laurent A, Bazin R, Flament F, Adam A, Coutet J, Piot B: Influence of season on some skin properties: winter vs. summer, as experienced by 354 Shanghaiese women of various ages. Int J Cosmet Sci 2011, 33:377-383.

73. Youn SW, Na Jl, Choi SY, Huh CH, Park KC: Regional and seasonal variations in facial sebum secretions: a proposal for the definition of combination skin type. Skin Res Technol 2005, 11:189-195.

74. Thorp AA, Owen N, Neuhaus M, Dunstan DW: Sedentary behaviors and subsequent health outcomes in adults a systematic review of longitudinal studies, 1996-2011. Am J Prev Med 2011, 41:207-215.

75. Pearson N, Biddle SJ: Sedentary behavior and dietary intake in children, adolescents, and adults a systematic review. Am J Prev Med 2011, 41:178-188.

76. Carnethon MR, Loria CM, Hill JO, Sidney S, Savage PJ, Liu K: Coronary Artery Risk Development in Young Adults study: Risk factors for the metabolic syndrome: the Coronary Artery Risk Development in Young Adults (CARDIA) study, 1985-2001. Diabetes Care 2004, 27:2707-2715

77. Hu G, Jousilahti P, Borodulin K, Barengo NC, Lakka TA, Nissinen A, Tuomilehto J: Occupational, commuting and leisure-time physical activity in relation to coronary heart disease among middle-aged Finnish men and women. Atherosclerosis 2007, 194:490-497.

78. Yoshioka M, Doucet E, St-Pierre S, Alméras N, Richard D, Labrie A, Després JP, Bouchard C, Tremblay A: Impact of high-intensity exercise on energy 
expenditure, lipid oxidation and body fatness. Int J Obes Relat Metab Disord 2001, 25:332-339.

79. Sisson SB, Camhi SM, Church TS, Martin CK, Tudor-Locke C, Bouchard C, Earnest CP, Smith SR, Newton RL Jr, Rankinen T, Katzmarzyk PT: Leisure time sedentary behavior, occupational/domestic physical activity, and metabolic syndrome in U.S. men and women. Metab Syndr Relat Disord 2009, 7:529-536.

80. Powers SK, Jackson MJ: Exercise-induced oxidative stress: cellular mechanisms and impact on muscle force production. Physiol Rev 2008, 88:1243-1276

81. Gerrior S, Bente L, Hiza H: Nutrient Content of the U.S. Food Supply, 19092000 (Home Economics Research Report No. 56). p A10-A12.

82. Jensen J, Rustad PI, Kolnes AJ, Lai YC: The role of skeletal muscle glycogen breakdown for regulation of insulin sensitivity by exercise. Front Physiol 2011, 2:112.

83. Aarsland A, Chinkes D, Wolfe RR: Hepatic and whole-body fat synthesis in humans during carbohydrate overfeeding. Am J Clin Nutr 1997, 65:1774-1782.

84. Konstantinov IE, Mejevoi N, Anichkov NM, Nikolai N: Anichkov and his theory of atherosclerosis. Tex Heart Inst J 2006, 33:417-423.

85. Kamezaki F, Sonoda S, Tomotsune Y, Yunaka H, Otsuji Y: Seasonal variation in metabolic syndrome prevalence. Hypertens Res 2010, 33:568-572.

86. Ockene IS, Chiriboga DE, Stanek EJ 3rd, Harmatz MG, Nicolosi R, Saperia G, Well AD, Freedson P, Merriam PA, Reed G, Ma Y, Matthews CE, Hebert JR: Seasonal variation in serum cholesterol levels: treatment implications and possible mechanisms. Arch Intern Med 2004, 164:863-870.

87. Robinson D, Bevan EA, Hinohara S, Takahashi T: Seasonal variation in serum cholesterol levels-evidence from the UK and Japan. Atherosclerosis 1992, 95:15-24.

88. Woodhouse PR, Khaw KT, Plummer M: Seasonal variation of serum lipids in an elderly population. Age Ageing 1993, 22:273-278.

89. Visscher TL, Seidell JC: Time trends (1993-1997) and seasonal variation in body mass index and waist circumference in the Netherlands. Int J Obes Relat Metab Disord 2004, 28:1309-1316.

90. Ma Y, Olendzki BC, Li W, Hafner AR, Chiriboga D, Hebert JR, Campbell M, Sarnie M, Ockene IS: Seasonal variation in food intake, physical activity, and body weight in a predominantly overweight population. Eur J Clin Nutr 2006, 60:519-528.

91. Rodondi N, Darioli R, Ramelet AA, Hohl D, Lenain V, Perdrix J, Wietlisbach V Riesen WF, Walther T, Medinger L, Nicod P, Desvergne B, Mooser V: High risk for hyperlipidemia and the metabolic syndrome after an episode of hypertriglyceridemia during 13-cis retinoic acid therapy for acne: a pharmacogenetic study. Ann Intern Med 2002, 136:582-589.

92. Metallinos-Katsaras E, Sherry B, Kallio J: Food insecurity is associated with overweight in children younger than 5 years of age. J Am Diet Assoc 2009, 109:1790-1794.

93. Karnik A, Foster BA, Mayer V, Pratomo V, McKee D, Maher S, Campos G, Anderson M: Food insecurity and obesity in New York City primary care clinics. Med Care 2011, 49:658-661.

94. Hakala P, Rissanen A, Koskenvuo M, Kaprio J, Rönnemaa T: Environmental factors in the development of obesity in identical twins. Int J Obes Relat Metab Disord 1999, 23:746-753.

95. Porter KN, Johnson MA: Obesity is more strongly associated with inappropriate eating behaviors than with mental health in older adults receiving congregate meals. J Nutr Gerontol Geriatr 2011, 30:403-415.

96. Furukawa S, Fujita T, Shimabukuro M, Iwaki M, Yamada Y, Nakajima Y, Nakayama O, Makishima M, Matsuda M, Shimomura I: Increased oxidative stress in obesity and its impact on metabolic syndrome. J Clin Invest 2004, 114:1752-1761.

97. Chen B, Wei J, Wang W, Cui G, Zhao Y, Zhu X, Zhu M, Guo W, Yu J: Identification of signaling pathways involved in aberrant production of adipokines in adipocytes undergoing oxidative stress. Arch Med Res 2009, 40:241-248

98. Otani $\mathrm{H}$ : Oxidative stress as pathogenesis of cardiovascular risk associated with metabolic syndrome. Antioxid Redox Signal 2011, 15:1911-1926.

99. Wu X, Duan X, Gu D, Hao J, Tao S, Fan D: Prevalence of hypertension and its trends in Chinese populations. Int J Cardiol 1995, 52:39-44.

100. Wu Z, Yao C, Zhao D, Wu G, Wang W, Liu J, Zeng Z: Cardiovascular disease risk factor levels and their relations to CVD rates in China-results of SinoMONICA project. Eur J Cardiovasc Prev Rehabil 2004, 11:275-283.
101. Shang $L$, Jiang $X$, Bao $X H$, Xue $F B, X u Y Y$ : Body mass index of male youths aged 18-20 years of the Han nationality living in different regions of China. J Health Popul Nutr 2007, 25:488-494.

102. Hayashi T, Ohshige K, Sawai A, Yamasue K, Tochikubo O: Seasonal influence on blood pressure in elderly normotensive subjects. Hypertens Res 2008, 31:569-574.

103. Kimura T, Senda S, Masugata H, Yamagami A, Okuyama H, Kohno T, Hirao T, Fukunaga M, Okada H, Goda F: Seasonal blood pressure variation and its relationship to environmental temperature in healthy elderly Japanese studied by home measurements. Clin Exp Hypertens 2010, 32:8-12.

104. Hozawa A, Kuriyama S, Shimazu T, Ohmori-Matsuda K, Tsuji I: Seasonal variation in home blood pressure measurements and relation to outside temperature in Japan. Clin Exp Hypertens 2011, 33:153-158.

105. Eisenhofer G, Kopin IJ, Goldstein DS: Catecholamine metabolism: a contemporary view with implications for physiology and medicine. Pharmacol Rev 2004, 56:331-349.

106. Kanikowska D, Sugenoya J, Sato M, Shimizu Y, Inukai $Y$, Nishimura N, Iwase S: Seasonal variation in blood concentrations of interleukin-6, adrenocorticotrophic hormone, metabolites of catecholamine and cortisol in healthy volunteers. Int J Biometeorol 2009, 53:479-485.

107. Radke KJ, Izzo JL: Seasonal variation in haemodynamics and blood pressure-regulating hormones. J Hum Hypertens 2010, 24:410-416.

108. World Health Organization: Pellagra and its prevention and control in major emergencies. Geneva, Switzerland; 2002, p 4. [http://www.who.int/ nutrition/publications/emergencies/WHO_NHD_00.10/en/index.html].

109. Higgins SP, Freemark M, Prose NS: Acanthosis nigricans: a practical approach to evaluation and management. Dermatol Online J 2008, 14:2.

110. Ice CL, Murphy E, Minor VE, Neal WA: Metabolic syndrome in fifth grade children with acanthosis nigricans: results from the CARDIAC project. World J Pediatr 2009, 5:23-30

111. Wofford MR, King DS, Harrell TK: Drug-induced metabolic syndrome. J Clin Hypertens (Greenwich) 2006, 8:114-119.

112. Mukhtar Q, Cleverley G, Voorhees RE, McGrath JW: Prevalence of acanthosis nigricans and its association with hyperinsulinemia in New Mexico adolescents. J Adolesc Health 2001, 28:372-376.

113. Yuspa SH: Cutaneous chemical carcinogenesis. J Am Acad Dermatol 1986, 15:1031-1044

114. Chowdhury R, Chatterjee R, Giri AK, Mandal C, Chaudhuri K: Arsenic-induced cell proliferation is associated with enhanced ROS generation, Erk signaling and CyclinA expression. Toxicol Lett 2010, 198:263-271.

115. Janiczek-Dolphin N, Cook J, Thiboutot D, Harness J, Clucas A: Can sebum reduction predict acne outcome?. Br J Dermatol 2010, 163:683-688.

116. Galobardes B, Davey Smith G, Jeffreys M, Kinra S, McCarron P: Acne in adolescence and cause-specific mortality: lower coronary heart disease but higher prostate cancer mortality: the Glasgow Alumni Cohort Study. Am J Epidemiol 2005, 161:1094-1101.

117. Gauglitz GG, Herndon DN, Kulp GA, Meyer WJ 3rd, Jeschke MG: Abnormal insulin sensitivity persists up to three years in pediatric patients post-burn. J Clin Endocrinol Metab 2009, 94:1656-1664.

118. Jeschke MG, Gauglitz GG, Kulp GA, Finnerty CC, Williams FN, Kraft R, Suman $\mathrm{OE}$, Mlcak RP, Herndon DN: Long-term persistance of the pathophysiologic response to severe burn injury. PLoS One 2011, 6:e21245.

doi:10.1186/1758-5996-4-15

Cite this article as: Zhou et al:: The skin function: a factor of antimetabolic syndrome. Diabetology \& Metabolic Syndrome 2012 4:15. 